\title{
OVCA1 expression and its correlation with the expression levels of cyclin D1 and p16 in cervical cancer and intraepithelial neoplasia
}

\author{
RUI TONG ${ }^{1,2}$, QING YANG ${ }^{1}$, CHUNYAN WANG $^{2}$, FANGFANG BI $^{1}$ and BING JIANG ${ }^{3}$ \\ ${ }^{1}$ Ward One of Minimally Invasive Gynecology, Nanhu Branch of Shengjing Hospital of China Medical University, Shenyang, \\ Liaoning 110004; ${ }^{2}$ Ward Four of Tumor Gynecology, Liaoning Cancer Hospital and Institute; ${ }^{3}$ Pathology Department, \\ Cancer Hospital of China Medical University, Liaoning Cancer Hospital and Institute, Shenyang, Liaoning 110042, P.R. China
}

Received August 19, 2015; Accepted December 2, 2016

DOI: $10.3892 / \mathrm{ol} .2017 .5848$

\begin{abstract}
The present study aimed to examine the associations between the protein and mRNA expression levels of ovarian cancer gene 1 (OVCA1), cyclin D1 and p16 and high-risk human papillomavirus (HR-HPV) infection in cervical lesions. The protein expression levels of OVCA1, cyclin D1 and p16 in 66 cases of cervical cancer, 64 cases of cervical intraepithelial neoplasia (CIN) and 34 normal cervix tissues were detected using immunohistochemistry. The mRNA expression levels of OVCA1, cyclin D1 and p16 in cervical cancer and normal cervix cells were detected using real-time polymerase chain reaction. The results revealed that the protein expression levels of OVCA1 increased gradually, whereas its mRNA expression levels decreased gradually, in the progression from normal cervix tissue to CIN and cervical cancer $(\mathrm{P}<0.01)$. In addition, significant differences in the protein expression levels of OVCA1 between low-and high-level CIN, as well as between the early and advanced stages of cervical cancer, were observed $(\mathrm{P}<0.05)$. No significant associations were detected between the protein and mRNA expression levels of OVCA1 and the pathological type of cervical cancer or the presence of lymph node metastasis $(\mathrm{P}>0.05)$. The expression levels of OVCA1 mRNA and protein were positively correlated with the levels of p16 expression $(\mathrm{P}<0.01)$. Significant differences were also observed in the OVCA1 protein and mRNA expression levels between the HR-HPV (+) and HR-HPV (-) groups $(\mathrm{P}<0.05)$. Therefore, aberrant expression of OVCA1 protein and mRNA may be important during the development of cervical lesions, particularly in the early stages. In addition, the mechanisms
\end{abstract}

Correspondence to: Mrs. Qing Yang, Ward One of Minimally Invasive Gynecology, Nanhu Branch of Shengjing Hospital of China Medical University, 36 Sanhao Street, Heping, Shenyang, Liaoning 110004, P.R. China

E-mail: yangqing_sj@163.com

Abbreviations: HR-HPV, high-risk human papillomavirus; CIN, cervical intraepithelial neoplasia

Key words: ovarian cancer gene 1, cyclin D1, p16, cervical cancer underlying the effects of OVCA1 during cervical cancer development may involve p16 and HPV, as the levels of OVCA1 in cervical lesions were correlated with abnormal expression of p16 and HR-HPV infection.

\section{Introduction}

Cervical cancer is the second most common cancer in females worldwide, ranking first in developing countries (1). In recent years, the incidence of cervical adenocarcinoma and cervical cancer in young women has increased significantly; therefore, early diagnosis is of high importance (2-8). High-risk human papillomavirus (HR-HPV) infection is an established cause of cervical cancer and this disease is preventable and treatable. Although extensive screening of cervical cancer enables early diagnosis and treatment in an increasing number of patients, the detection of cervical cancer using the HR-HPV ThinPrep cytology test may lead to overtreatment and misdiagnosis, which may also impede prevention and therapeutic intervention. Furthermore, the clinical outcomes of the same treatment for similar pathological types of cervical cancer are heterogeneous (9). Therefore, an effective molecular marker of cervical lesions is required to supplement screening for cervical cancer, in order to allow the development of individual treatment regimens for various molecular types and improve the prevention and treatment of cervical cancer.

Ovarian cancer gene 1 (OVCA1) is a cancer suppressor that may be correlated with the occurrence and development of ovarian and cervical cancer, particularly in early lesions (10). The inhibition of OVCA1 may be associated with the regulation and control of the cell cycle, leading to cell cycle arrest at the $\mathrm{G}_{1} / \mathrm{S}$ phase and, thus, suppressing cell proliferation $(11,12)$. Aberrant expression of OVCA1 mRNA has been detected in cervical cancer (13). However, the expression levels of OVCA1, as well as its association with the clinical pathology and its underlying mechanisms of action, remain to be elucidated.

The current study aimed to evaluate molecular biomarkers for the diagnosis and treatment of cervical lesions through detection of the protein and mRNA expression levels of OVCA1, cyclin D1 and p16 in cervical cancer, cervical intraepithelial neoplasia (CIN) and normal cervix tissue. In addition, the associations between OVCA1 expression and HR-HPV infection were examined, in order to examine the 
potential mechanisms underlying the involvement of OVCA1 in the development of cervical lesions.

\section{Materials and methods}

Patients. In total, 130 female patients with cervical lesions who were pathologically diagnosed between February 2014 and July 2014 at Liaoning Cancer Hospital and Institute (Shenyang, China) were selected, including 66 cases of cervical cancer and 64 cases of CIN. All pathological sections were reviewed by a pathologist (Liaoning Cancer Hospital and Institute). In addition, 34 normal cervix tissue specimens obtained from patients with hysteromyoma, ovarian cysts and other non-malignant tumors with hysterectomy were selected as controls. The present study was approved by Liaoning Cancer Hospital Ethics Committee, and all patients provided informed consent prior to biopsy surgery.

The clinical stages of cervical cancer were classified according to the 2009 International Federation of Gynecology and Obstetrics staging system $(9,14)$. Of the 66 cases of cervical cancer, 20 cases were stage I, 8 were stage II, 34 were stage III and 4 were stage IV. The cases included 60 of squamous carcinoma and 6 of adenocarcinoma. The pathological grades were as follows: 20 cases of high differentiation (G1), 42 cases of moderate differentiation (G2) and 4 cases of low differentiation (G3). In total, there were 31 cases with lymph node metastasis and 35 cases without lymph node metastasis. In addition, 64 cases of CIN were graded according to the Richart Pathology criteria $(9,15-17)$ as follows: 22 cases of CIN1, 22 cases of CIN2 and 20 cases of CIN3. Among the 164 cervical cancer, CIN and control patients, HR-HPV infection was detected in 103 cases and undetected in 61 cases. All patients had no contraindications and received no radiotherapy or chemotherapy prior to biopsy.

Two biopsy tissue specimens (3-8-mm thick) were obtained for each patient with cervical cancer and each healthy patient with normal cervical tissue. The first was fixed in $4 \%$ paraformaldehyde for immunohistochemistry tissue microarray analysis. The second tissue specimen was stored in at $-80^{\circ} \mathrm{C}$ for reverse transcription-quantitative polymerase chain reaction (RT-qPCR) analysis. Following lymph node excision, lymph nodes of $>1 \mathrm{~cm}$ that had been deemed highly suggestive of metastasis preoperatively using computed tomography/magnetic resonance imaging were determined to be cases of lymph node metastasis. Prior to treatment, the presence of HPV infection was determined from cervical screening using hybrid capture II (HC-II; Qiagen, Inc., Valencia, CA, USA) and values of $>1.0$ relative light units/cutoff were defined as HR-HPV-positive.

Reagents and instruments. The antibodies used were as follows: Mouse anti-human OVCA1 (\#ab54777; Abcam, Cambridge, UK), mouse anti-human p16 (\#ZM-0205; OriGene Technologies, Inc., Beijing, China) and mouse anti-human cyclin D1 (\#sc-8396; Santa Cruz Biotechnology, Inc., Dallas, TX, USA). The High-Capacity cDNA Reverse Transcription kit was purchased from Thermo Fisher Scientific, Inc. (Waltham, MA, USA) and the PrimeScript ${ }^{\mathrm{TM}}$ RT-PCR kit was purchased from Takara Bio, Inc. (Otsu, Japan). TRIzol ${ }^{\circledR}$ RNA Isolation reagent was purchased from Invitrogen (Thermo Fisher
Scientific,Inc.). Primers for OVCA1, cyclin D1, p16 and GAPDH (internal control) were designed and synthesized by Invitrogen (Thermo Fisher Scientific, Inc.). Immunohistochemistry imaging was performed using NIS-Elements F3.0 software for image acquisition, and image analysis utilized NIS-Elements Br3.0 software (Nikon Corporation, Tokyo, Japan). The PCR instrument was produced by Bio-Rad Laboratories, Inc. (Hercules, CA, USA).

Immunohistochemistry. The representative regions of normal cervix, CIN and cervical cancer in paraffin-embedded specimens were labeled according to the hematoxylin and eosin-stained sections. Subsequently, tissue microarrays of cervical cancer, CIN and normal cervical tissues were constructed, and all the representative points were included in three arrays $(10 \times 8,10 \times 6$ and $8 \times 3)$. The dilutions of primary antibodies were 1:50 (OVCA1), 1:100 (cyclin D1) and 1:200 (p16). Immunohistochemical staining was performed using a PicTure $^{\mathrm{TM}}$ Two-Step Immunohistochemistry kit (OriGene Technologies, Inc., Beijing, China) according to the manufacturer's protocol. PBS was used to replace primary antibody as a negative control, and cervical cancer tissue sections with established cyclin D1- and p16-positive staining were used as positive controls, whereas no positive control was established for OVCA1. The presence of translucent brown granules in the nucleus and cytoplasm was determined to indicate positivity for OVCA1, cyclin D1 and p16. Abnormal OVCA1 and p16 proteins were detected using immunohistochemistry. Positive staining for OVCA1 was localized to the nucleus and cytoplasm, primarily surrounding the nucleus. CyclinD1 staining was primarily localized to the nucleus, as well as being observed in the cytoplasm, whereas p16 staining was localized to the nucleus and cytoplasm. In total, 5 representative fields from each pathological section were examined under high magnification using a scanning electron microscope (Nikon E800; Nikon Corporation) to detect the average optical density (OD) and color rendering area (S) of each field. The integral OD (IOD) was calculated as ODxS, and the average IOD of each pathological section was determined. The results were judged semi quantitatively.

$R T-q P C R$. Total RNA was extracted from normal cervix and cervical cancer tissue samples using TRIzol, and the OD of the RNA samples, as detected using an ultraviolet spectrophotometer at an absorbance of 260-280 nm, was $\sim 1.8-2.0$. The RNA bands were separated using $1.5 \%$ agarose gel electrophoresis. The process of cDNA synthesis was performed according to the manufacturer's protocol. Briefly, reaction mixtures were prepared, which consisted of $4 \mu 1$ RNA samples treated with DNase (Takara Bio, Inc.), $2 \mu \mathrm{l}$ of 5X PrimeScript ${ }^{\circledR}$ RT Master mix and $4 \mu \mathrm{l}$ diethylpyrocarbonate (DEPC)-treated water. The reactions were incubated for $15 \mathrm{~min}$ at $37^{\circ} \mathrm{C}$ and $5 \mathrm{sec}$ at $4^{\circ} \mathrm{C}$, and the cDNA was subsequently used as a template for RT-qPCR or stored at $-70^{\circ} \mathrm{C}$.

RT-qPCR reaction mixtures were composed of $10 \mu 1 \mathrm{SYBR}$ Green, $6 \mu \mathrm{l}$ DEPC-treated water, $2.0 \mu \mathrm{l}$ cDNA template and $2.0 \mu \mathrm{l}$ of each $10 \mu \mathrm{M}$ primers (total primer volume, $20 \mu \mathrm{l}$ ). The primer sequences were as follows: OVCA1 forward, 5'-CTG AGGTGGATGTGTGGGTG-3' and reverse, 5'-CCTCAT AGGGTGTCAGCAGC-3'; cyclin D1 forward, 5'-CCCTCG 
GTGTCCTACTTC-3' and reverse, 5'-AGGAAGCGGTCC AGGTAGTT-3'; p16 forward, 5'-GTGGACCTGGCTGAG GAG-3' and reverse, 5'-CTTTCAATCGGGGATGTCTG-3'; and GAPDH forward, 5'-AGGTGAAGGTCGGAGTCA-3' and reverse, 5'-GGTCATTGATGGCAACAA-3'. The thermocycling conditions consisted of an initial step for $5 \mathrm{~min}$ at $94^{\circ} \mathrm{C}$, followed by 40 cycles of denaturation for $5 \mathrm{sec}$ at $94^{\circ} \mathrm{C}$ and annealing for $30 \mathrm{sec}$ at $60^{\circ} \mathrm{C}$. The results were analyzed using the $\Delta \Delta \mathrm{Cq}$ relative quantification method (18), with GAPDH as the reference gene. The $\Delta \mathrm{Cq}$ values for the experimental group and the control group were calculated according to the formula: $\Delta \mathrm{Cq}=\mathrm{Cq}$ (target gene)- $\mathrm{Cq}$ (reference gene). Subsequently, according to the formula $\Delta \Delta \mathrm{Cq}=\Delta \mathrm{Cq}$ (experiment group) $-\Delta \mathrm{Cq}$ (control group), $\Delta \Delta \mathrm{Cq}$ was calculated, and the difference in relative mRNA expression $\left(2^{-\Delta \Delta \mathrm{Cq}}\right)$, was obtained.

Statistical analysis. One-way analysis of variance, the Mann-Whitney U rank sum test and Spearman's correlation analysis were applied to analyze the data using SPSS version 19.0 (IBM SPSS, Armonk, NY, USA). P<0.05 was considered to indicate a statistically significant difference.

\section{Results}

Protein expression of OVCA1, cyclin D1 and pl6 in various cervical tissues. The IOD values of the OVCA1 $(\mathrm{P}<0.01)$, cyclin $\mathrm{D} 1(\mathrm{P}<0.01)$ and $\mathrm{p} 16(\mathrm{P}<0.01)$ protein bands increased from the normal cervix to CIN and cervical cancer tissues. Following further pairwise comparisons, a statistically significant difference was observed in the OVCA1 and p16 expression levels between normal and cancer tissues $(\mathrm{P}<0.01)$, normal and CIN tissues $(\mathrm{P}<0.01)$ and $\mathrm{CIN}$ and cancer tissues $(\mathrm{P}<0.01)$, and in the protein expression levels of cyclin D1 between normal and cancer tissues $(\mathrm{P}<0.01)$ and $\mathrm{CIN}$ and cancer tissues $(\mathrm{P}<0.01)$. Conversely, no significant difference in the expression levels of cyclin D1 was observed between normal and $\mathrm{CIN}$ tissues ( $\mathrm{P}=0.136$; Table I; Fig. 1A).

Associations between the protein expression levels of OVCA1, cyclin D1 and p16 and clinical features. The protein expression levels of OVCA1 in high-level CIN tissues (CIN2-3) were significantly higher compared with low-level CIN tissues (CIN1; $\mathrm{P}=0.031,<0.05$ ), whereas no significant differences were observed in cyclin D1 and p16 expression levels between the high and low-level CIN groups $\left(\mathrm{P}_{\text {cyclin DI }}=0.977 ; \mathrm{P}_{\mathrm{p} 16}=0.056\right.$; Table II). The protein expression levels of OVCA1, cyclin D1 and p16 in advanced-stage (II-IV) cervical cancer were significantly higher compared with early-stage cervical cancer (I; $\mathrm{P}_{\text {OVCAI }}=0.016 ; \mathrm{P}_{\text {cyclin DI }}=0.001 ; \mathrm{P}_{\mathrm{p} 16}=0.005$; Table II).

The protein expression levels of OVCA1 and p16 in the HR-HPV (+) group were significantly higher, as compared with the HR-HPV (-) group $\left(\mathrm{P}_{\mathrm{OVCA} 1}<0.01 ; \mathrm{P}_{16}<0.01\right.$; Table II). The expression levels of p16 protein in adenocarcinoma were higher compared with those detected in squamous carcinoma ( $\mathrm{P}=0.030$; Table II). No statistically significant differences $(\mathrm{P}=0.933)$ were identified in the protein expression levels of cyclin D1 between the HR-HPV (+) and HR-HPV (-) groups. In addition, no statistically significant differences in OVCA1 and cyclin D1 protein expression levels were identified between various pathological types, as well as in OVCA1, cyclin D1 and p16 protein expression levels between the groups with or without lymph node metastasis and between pathological grades $\left(\mathrm{G} 1 / \mathrm{G} 2 / \mathrm{G} 3 ; \mathrm{P}_{\text {OvCAl }}=0.799 ; \mathrm{P}_{\text {cyclin D1 }}=0.496 ; \mathrm{P}_{\mathrm{pl}}=0.617\right.$; Table II; Fig. 1B and C). Intense positive staining was observed in the cytoplasm of the koilocytes in the tissue samples, which was indicative of HPV infection (Fig. 1D).

Associations between the protein expression levels of OVCA1, cyclin D1 and p16. The IOD values of the OVCA1, cyclin D1 and 16 proteins in the normal cervix, CIN and cervical cancer tissues increased as the lesions progressed towards malignancy. Positive staining for OCVA1 protein was significantly positively correlated with that of cyclin $\mathrm{D} 1$ and $\mathrm{p} 16\left(\mathrm{P}_{\mathrm{OVCA}}\right.$, cyclin D1 $<0.01 ; \mathrm{P}_{\mathrm{OVCA}, \mathrm{p} 16}<0.01$ ), and staining for cyclin D1 and p16 were positively correlated $\left(\mathrm{P}_{\mathrm{p} 16}\right.$ \& cyclin D1 $<0.01$; Table III).

OVCA1, cyclin D1 and p16 mRNA expression levels in cervical cancer and normal cervix tissues. The relative mRNA expression levels of OVCA1 and p16 in cervical cancer tissues were lower compared with that in normal cervix tissues $\left(\mathrm{P}_{\text {OVCA1 }}<0.01 ; \mathrm{P}_{\mathrm{p} 16}=0.005\right)$. In addition, the relative cyclin D1 mRNA expression levels were higher in cervical cancer tissues compared with normal cervix tissues $\left(\mathrm{P}_{\text {cyclin Dl }}<0.01\right.$; Table IV).

Associations between the mRNA expression levels of OVCA1, cyclin D1 and p16 and clinical features. The mRNA expression levels of OVCA1 decreased gradually from low- to moderately- and highly-differentiated cervical cancer tissues $(\mathrm{P}=0.012)$ and were significantly lower in the HR-HPV $(+)$ group compared with the HR-HPV (-) group $(\mathrm{P}<0.01)$. No significant differences were observed in the cyclin D1 and p16 expression levels between various pathological grades and between the HR-HPV (+) and HR-HPV (-) groups $\left(\mathrm{P}_{\text {cyclin D1-pathological grades }}=0.359 ; \mathrm{P}_{\text {cyclin D1-HPV }}=0.250 ; \mathrm{P}_{\mathrm{p} 16 \text {-pathological }}\right.$ grades $\left.=0.481 ; \mathrm{P}_{\mathrm{p} 16-\mathrm{HPV}}=0.411\right)$. No significant differences were identified in the mRNA expression levels of OVCA1, cyclin D1 and p16 between the various stages and pathological types of cervical cancer, and the presence or absence of lymph node metastasis (Table V).

Associations between the mRNA expression levels of OVCA1, cyclin D1 and p16. The relative mRNA expression levels of OVCA1 and p16 were decreased as the lesions progressed, and there was a positive correlation between them $(\mathrm{P}=0.007)$. The relative expression levels of cyclin D1 mRNA increased as lesions progressed; however, no correlation was identified between OVCA1 and cyclin D1 and between cyclin D1 and p16 mRNA expression levels $\left(\mathrm{P}_{\text {OvCA1 \& cyclin D1 }}=0.845\right.$; $\mathrm{P}_{\mathrm{p} 16 \text { \& cyclin D1 }}=0.471$; Table VI).

\section{Discussion}

Although pathological detection remains the gold standard for the diagnosis of cervical cancer, it is an invasive examination, with a lack of consensus between pathologists, low reproducibility rates for diagnosis and a high rate of misdiagnosis of early or focal lesions $(19,20)$. At present, persistent HR-HPV infection is a recognized pathogenic factor of cervical cancer, but HR-HPV infection alone is not sufficient to cause cervical cancer, with few HR-HPV-infected individuals developing 
Table I. Expression levels of OVCA1, cyclin D1 and p16 proteins in various cervical tissues (IOD value).

\begin{tabular}{lrrrrrrr}
\hline Group & \multicolumn{1}{c}{$\begin{array}{c}\text { IOD value, } \\
\text { OVCA1 }\end{array}$} & \multicolumn{1}{c}{$\begin{array}{c}\text { F-value/ } \\
\text { P-value }\end{array}$} & $\begin{array}{c}\text { IOD value, } \\
\text { cyclin D1 }\end{array}$ & $\begin{array}{c}\text { F-value/ } \\
\text { P-value }\end{array}$ & $\begin{array}{r}\text { IOD value, } \\
\text { p16 }\end{array}$ & $\begin{array}{c}\text { F-value/ } \\
\text { P-value }\end{array}$ \\
\hline Normal tissue & 34 & $44,318.68$ & $13.703^{\mathrm{a}} /<0.001^{\mathrm{a}}$ & $342,846.11$ & $2.26^{\mathrm{a}} / 0.136^{\mathrm{a}}$ & $42,779.59$ & $19.53^{\mathrm{a}} /<0.001^{\mathrm{a}}$ \\
CIN & 64 & $71,011.03$ & $73.078^{\mathrm{b}} /<0.001^{\mathrm{b}}$ & $41,502.09$ & $11.88^{\mathrm{b}} /<0.001^{\mathrm{b}}$ & $88,331.77$ & $126.11^{\mathrm{b}} /<0.001^{\mathrm{b}}$ \\
Cervical cancer & 66 & $120,093.60$ & $159.949^{\mathrm{c}} /<0.001^{\mathrm{c}}$ & $60,090.93$ & $13.57^{\mathrm{c}} /<0.001^{\mathrm{c}}$ & $172,974.76$ & $445.76^{\mathrm{c}} /<0.001^{\mathrm{c}}$ \\
Total & 164 & $85,229.99$ & $73.914^{\mathrm{d}} /<0.001^{\mathrm{d}}$ & $47,486.97$ & $10.84^{\mathrm{d}} /<0.001^{\mathrm{d}}$ & $112,951.67$ & $130.82^{\mathrm{d}} /<0.001^{\mathrm{d}}$ \\
\hline
\end{tabular}

${ }^{\mathrm{a} C I N}$ vs. normal; ${ }^{\mathrm{b}}$ cervical cancer vs. CIN; ${ }^{\mathrm{c} e r v i c a l}$ cancer vs. normal; ${ }^{\mathrm{d}}$ overall comparison. CIN, cervical intraepithelial neoplasia; p16, tumor protein 16; IOD, integrated optical density; OVCA1, ovarian cancer gene 1.

cancer. The detection of HR-HPV lacks specificity for the detection of cancer; therefore, medical interventions to combat HR-HPV infection may cause patient distress and overtreatment $(19,20)$.

Advancements in molecular biology techniques have allowed an improved understanding of the occurrence and development of tumor sat the genetic level (21). If molecular factors that are associated with tumor development are identified, the accuracy of early diagnosis and severity evaluation of cervical lesions may improve, providing a reference for the prevention and treatment of cervical cancer.

First identified by Schultz et al (22) using positional cloning, the OVCA1 gene is a tumor suppressor gene localized to17p13.3 that is widely expressed in various human tissues. OVCA1 is transcribed as a $213 \mathrm{~kb}$ mRNA molecule, and translated to a protein encoding 443 amino acids; its subcellular localization is surrounding the nucleus, and its gene products in mammals are highly conserved (21). Increased OVCA1 protein is able to inhibit the growth of tumor cells significantly, and small alterations in its gene expression levels may lead to anomalies of the cell cycle, promoting tumor development (10). A loss of heterozygosity in the OVCA1 gene has been detected in ovarian, breast and cervical cancer (23-25), as well as other tumors (26-30), indicating its potential role in the development of various malignant tumors. In addition, previous studies have demonstrated that OCVA1 is important in tumorigenesis, cell proliferation, maintaining the normal growth of animals and inhibiting apoptosis, metastasis and cell invasion $(31,32)$.

In previous studies, the mRNA and protein expression levels of the OVCA1 gene were decreased significantly or were lost in ovarian cancer tissues and cell lines, as compared with normal ovarian tissues, via an underlying mechanism that may be correlated with the downregulation of cyclin D1 and upregulation of p16 expression (33-35).

High-frequency anomalies at the OVCA1 gene locus are a feature of cervical cancer, and anomaly of number is as common as that of structure. These abnormalities occur at an earlier stage than p53 mutations, which are localized nearby (17p13.1). This indicates that the deletion of OVCA1 in cervical cancer may be correlated with cervical cancer progression, and appears at the early-stage of disease $(36,37)$. The detection of OVCA1 deletions may contribute to the understanding of the molecular mechanisms underlying the occurrence and development of cervical lesions at the early stages. A previous study by Zhu (13) revealed that the rate
A a OVCA1-CA

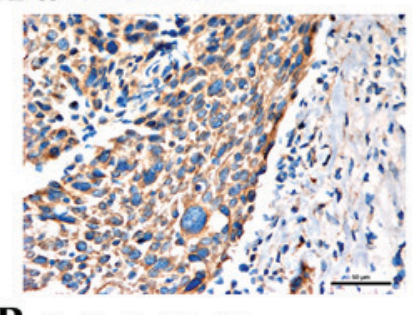

B a CyclinD1-CA

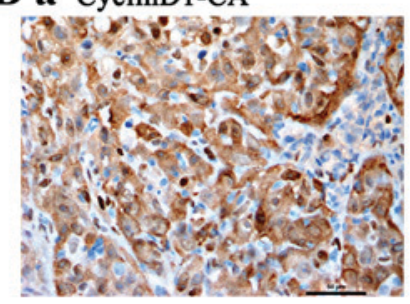

\section{C a P16-CA}

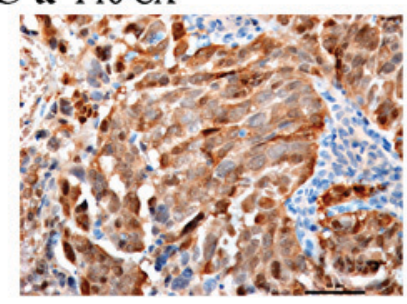

D

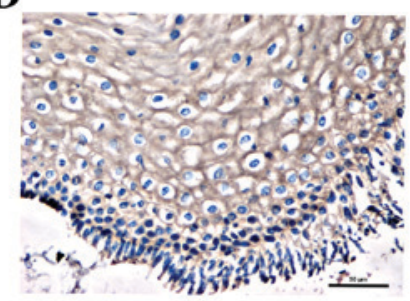

b OVCA1-CIN

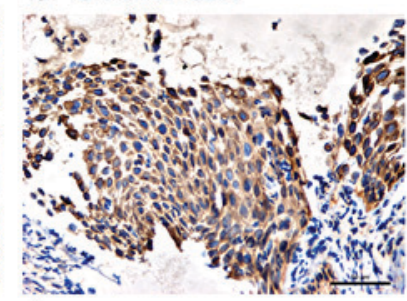

b CyclinD1-CIN

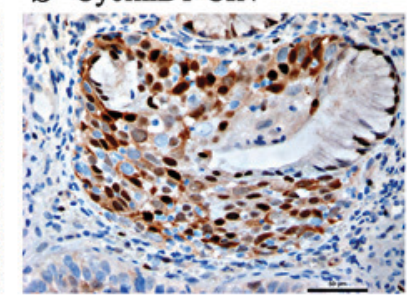

b P16-CIN

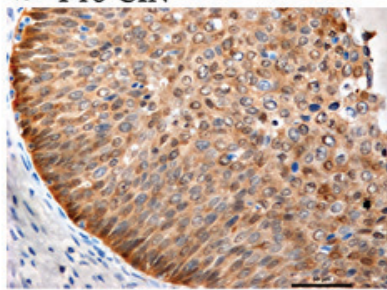

Figure 1. Positive immunohistochemical staining for OVCA1, cyclin D1 and p16 in cervical cancer and CIN. (A) Positive expression of OVCA1 in (a) cervical cancer, tissue and (b) CIN tissue. (B) Positive expression of cyclin D1 in (a) cervical cancer tissue and (b) CIN tissue. (C) Positive expression of p16 in (a) cervical cancer tissue and (b) CIN tissue. (D) Positive expression of OVCA1 in koilocytes of cervical cancer tissue. Magnification, 400x. CIN, cervical intraepithelial neoplasia; OVCA1, ovarian cancer gene 1.

of loss of all exons of the OVCA1 gene in cervical cancer tissue was higher compared with normal tissue, and that loss 
Table II. Correlations between the protein expression levels of OVCA1, cyclin D1 and p16 and various clinicopathological features.

\begin{tabular}{|c|c|c|c|c|c|c|c|}
\hline Group & $\mathrm{n}$ & $\begin{array}{l}\text { IOD value, } \\
\text { OVCA1 }\end{array}$ & $\begin{array}{l}\text { Z/F-value } \\
\text { P-value }\end{array}$ & $\begin{array}{l}\text { IOD value, } \\
\text { cyclin D1 }\end{array}$ & $\begin{array}{l}\text { Z/F-value } \\
\text { P-value }\end{array}$ & $\begin{array}{l}\text { IOD value, } \\
\text { p16 }\end{array}$ & $\begin{array}{c}\mathrm{Z} / \mathrm{F} \text {-value } \\
\mathrm{P} \text {-value }\end{array}$ \\
\hline \multicolumn{8}{|l|}{ CIN level } \\
\hline CIN 1 & 22 & $51,995.00$ & -2.941 & $42,772.36$ & -0.280 & $69,577.02$ & -1.908 \\
\hline CIN 2-3 & 42 & $80,971.81$ & $0.031^{\mathrm{a}}$ & $41,664.49$ & 0.977 & $98,155.69$ & 0.056 \\
\hline \multicolumn{8}{|l|}{$\begin{array}{l}\text { FIGO clinical stage of } \\
\text { cervical cancer }\end{array}$} \\
\hline Stage I & 20 & $109,356.18$ & -2.401 & $36,212.49$ & -3.471 & $159,454.92$ & -2.832 \\
\hline Stage II-IV & 46 & $124,762.04$ & $0.016^{\mathrm{a}}$ & $70,472.35$ & $<0.001^{\mathrm{b}}$ & $178,852.94$ & $0.005^{\mathrm{b}}$ \\
\hline \multicolumn{8}{|l|}{ Pathological grade } \\
\hline G1 & 20 & $123,756.57$ & 0.251 & $63,685.25$ & 0.496 & $170,175.84$ & 0.486 \\
\hline G2 & 42 & $118,751.72$ & 0.779 & $63,685.25$ & 0.496 & $176,783.05$ & 0.617 \\
\hline G3 & 4 & $115,868.47$ & & $73,442.64$ & & $172,357.07$ & \\
\hline \multicolumn{8}{|l|}{ Pathological type } \\
\hline Squamous carcinoma & 60 & $120,694.21$ & -1.026 & $66,669.11$ & -0.580 & $170,586.98$ & -2.164 \\
\hline Adenocarcinoma & 6 & $114,087.48$ & 0.305 & $64,282.41$ & 0.562 & $196,852.47$ & $0.030^{\mathrm{a}}$ \\
\hline \multicolumn{8}{|l|}{ Lymph node metastasis } \\
\hline Positive & 31 & $123,897.14$ & -1.774 & $70,232.35$ & -2.211 & $173,387.03$ & -0.084 \\
\hline Negative & 35 & $116,724.75$ & 0.076 & $51,108.52$ & 0.027 & $172,609.60$ & 0.933 \\
\hline \multicolumn{8}{|l|}{ HPV } \\
\hline Positive & 103 & $94,994.85$ & -3.934 & $49,858.21$ & 0.864 & $127,905.46$ & -3.479 \\
\hline Negative & 61 & $68,741.79$ & $<0.01^{\mathrm{b}}$ & $43,483.07$ & 0.387 & $87,701.82$ & $0.001^{\mathrm{b}}$ \\
\hline
\end{tabular}

${ }^{\mathrm{a}} \mathrm{P}<0.05,{ }^{\mathrm{b}} \mathrm{P}<0.01$. IOD, integrated optical density; CIN, cervical intraepithelial neoplasia; FIGO, International Federation of Gynecology and Obstetrics; HPV, human papillomavirus; OVCA1, ovarian cancer gene 1.

Table III. Correlations between OVCA1, cyclin D1 and p16 protein expression levels.

\begin{tabular}{lccccc}
\hline & \multicolumn{2}{c}{ Cyclin D1 } & & \multicolumn{2}{c}{$\mathrm{p} 16$} \\
\cline { 2 - 3 } \cline { 5 - 6 } & $\mathrm{r}$ & P-value & & $\mathrm{r}$ & P-value \\
\hline OVCA1 & 0.249 & $0.001^{\mathrm{a}}$ & & 0.618 & $<0.001^{\mathrm{a}}$ \\
Cyclin D1 & - & - & & 0.336 & $<0.01^{\mathrm{a}}$ \\
\hline
\end{tabular}

${ }^{\mathrm{a}} \mathrm{P}<0.01$. OVCA1, ovarian cancer gene 1 .

rates of the exons of the OVCA1 gene in HPV16/18 positive individuals were higher compared with HPV16/18 negative individuals. In addition, the relative OVCA1 mRNA expression levels were higher in HPV16/18 positive cervical cancer tissues compared with HPV16/18 negative samples; however, this difference was not significantly significant (13). The relative OVCA1 mRNA expression levels in cervical cancer tissues were significantly decreased compared with those in normal tissues (13). Aberrant OVCA1 expression may occur at the mRNA or protein level. To the best of our knowledge, no studies have been conducted to examine the protein expression levels of OVCA1 in cervical cancer and their association
Table IV. Relative expression levels of OVCA1, cyclin D1 and p16 mRNA in normal cervix and cervical cancer tissues.

\begin{tabular}{lcccc}
\hline Group & OVCA1, & cyclin D1, & $\mathrm{p} 16$, \\
$\Delta \Delta \mathrm{Cq}$ & $\Delta \Delta \mathrm{Cq}$ \\
\hline Normal tissue & 34 & 1.07 & 1.25 & 0.94 \\
Cervical cancer & 66 & 0.64 & 1.98 & 0.72 \\
Z-value & & -5.520 & -3.247 & -2.825 \\
P-value & & $<0.001^{\mathrm{a}}$ & $0.001^{\mathrm{a}}$ & $0.005^{\mathrm{a}}$ \\
\hline
\end{tabular}

${ }^{\mathrm{a}} \mathrm{P}<0.01$. OVCA1, ovarian cancer gene 1 .

with cancer stage, pathological grades, histological classification and HPV infection status.

The current study revealed that the protein expression levels of OVCA1 increased gradually in normal cervix, CIN and cervical cancer tissues $(\mathrm{P}<0.05)$, whereas mRNA expression decreased gradually $(\mathrm{P}<0.05)$. The protein and mRNA expression levels of OVCA1 in cervical cancer exhibited statistically significant differences between the early and advanced stages $(\mathrm{P}<0.05)$, and the protein expression levels exhibited statistically significant differences between CIN1 and CIN2/3 $(\mathrm{P}<0.05)$, indicating that OVCA1 may function during the 
Table V. Correlations between OVCA1, cyclin D1 and p16 mRNA expression levels and various clinicopathological features.

\begin{tabular}{|c|c|c|c|c|c|c|c|}
\hline Group & $\mathrm{n}$ & $\begin{array}{l}\text { OVCA } 1 \\
\Delta \Delta \mathrm{Cq}\end{array}$ & $\begin{array}{l}\mathrm{Z} / \mathrm{F} \text { value } \\
\mathrm{P} \text {-value }\end{array}$ & $\begin{array}{c}\text { Cyclin D1, } \\
\Delta \Delta \mathrm{Cq}\end{array}$ & $\begin{array}{l}\mathrm{Z} / \mathrm{F} \text { value } \\
\mathrm{P} \text {-value }\end{array}$ & $\begin{array}{c}\mathrm{p} 16 \\
\Delta \Delta \mathrm{Cq}\end{array}$ & $\begin{array}{l}\mathrm{Z} / \mathrm{F} \text { value } \\
\mathrm{P} \text {-value }\end{array}$ \\
\hline \multicolumn{8}{|c|}{$\begin{array}{l}\text { FIGO clinical stage of } \\
\text { cervical cancer }\end{array}$} \\
\hline Stage I & 20 & 0.71 & -0.671 & 1.78 & -0.614 & 0.80 & -1.173 \\
\hline Stage II-IV & 46 & 0.61 & 0.502 & 2.04 & 0.539 & 0.69 & 0.241 \\
\hline \multicolumn{8}{|c|}{ Pathological grade } \\
\hline G1 & 20 & 0.30 & 4.487 & 1.79 & 1.043 & 0.75 & 0.740 \\
\hline $\mathrm{G} 2$ & 42 & 0.76 & $0.012^{\mathrm{a}}$ & 2.12 & 0.359 & 0.73 & 0.481 \\
\hline G3 & 4 & 1.04 & & 1.17 & & 0.53 & \\
\hline \multicolumn{8}{|c|}{ Lymph node metastasis } \\
\hline Positive & 31 & 0.68 & -0.328 & 1.91 & -0.129 & 0.62 & -0.926 \\
\hline Negative & 35 & 0.60 & 0.743 & 2.00 & 0.898 & 0.81 & 0.355 \\
\hline \multicolumn{8}{|l|}{ HPV } \\
\hline Positive & 103 & 0.53 & -5.753 & 1.80 & -1.132 & 0.78 & -0.822 \\
\hline Negative & 61 & 1.15 & $<0.001^{\mathrm{b}}$ & 2.29 & 0.250 & 0.62 & 0.411 \\
\hline
\end{tabular}

${ }^{\mathrm{a}} \mathrm{P}<0.05,{ }^{\mathrm{b}} \mathrm{P}<0.01$. FIGO, International Federation of Gynecology and Obstetrics; HPV, human papillomavirus; OVCA1, ovarian cancer gene 1.

process of cervical lesion development, particularly at the early stages. There was a statistically significant difference between OVCA1 protein and mRNA expression levels between the HR-HPV (+) and HR-HPV (-) groups $(\mathrm{P}<0.05)$. Therefore, the aberrant expression of OVCA1 in cervical lesions may be correlated with HR-HPV infection, and HR-HPV infection may function during the intermediate processes underlying cervical carcinogenesis. In addition, the present study detected positive expression of OVCA1 in the HR-HPV (+) normal cervix tissue and CIN1 tissue, whereas intense positive expression was observed in koilocytes, which indicated the presence of HPV infection. Therefore, the current study hypothesizes that, prior to triggering morphological changes to cells, HR-HPV infection may promote the abnormal expression of OVCA1 mRNA and protein. Furthermore, the detection of OVCA1 expression may aid the triage of diagnosis and the treatment of HR-HPV-infected patients, as well as improving the detection rate of CIN and cervical cancer at early stages. However, OVCA1 positive expression was detected in HR-HPV (-) cases, which indicates that the causes of abnormal OVCA1 expression may not be limited to HR-HPV infection. The expression levels of OVCA1mRNA significantly increased from the high to moderate to low differentiation cervical cancer groups $(\mathrm{P}<0.05)$, and abnormal OVCA1 mRNA expression was more common in well-differentiated cases at the early stage, but there was no difference at the protein level. Therefore, further studies with increased sample sizes are required.

Disorders of the cell cycle and the uncontrolled growth of cells are primary mechanisms underlying tumorigenesis. As a positive regulatory factor, cyclin is a convergent point of numerous oncogenes and tumor suppressor genes, serving a key role in the regulation of cell cycle events (38).

CyclinD1 is localized in the 11q13 chromosomal region and is a regulatory nuclear protein, as well as being an established potential oncogene, as its c-terminus has a PEST
Table VI. Correlations between OVCA1, cyclin D1 and p16 mRNA expression levels.

\begin{tabular}{lccrrr}
\hline & \multicolumn{2}{c}{ Cyclin D1 } & & \multicolumn{2}{c}{$\mathrm{p} 16$} \\
\cline { 2 - 3 } \cline { 5 - 6 } & $\mathrm{r}$ & P-value & & $\mathrm{r}$ & P-value \\
\hline OVCA1 & 0.20 & 0.845 & & 0.286 & $0.007^{\mathrm{a}}$ \\
Cyclin D1 & - & - & & -0.073 & 0.471 \\
\hline
\end{tabular}

${ }^{\mathrm{a}} \mathrm{P}<0.01$. OVCA1, ovarian cancer gene 1 .

sequence that is important in the cellular transformation process (39). As a G1-stage cyclin, cyclin D1 is important for $\mathrm{G}_{1} / \mathrm{S}$-stage transformation of the cell cycle. Following DNA synthesis, cyclinD1 forms a complex with cyclin-dependent kinase (CDK) 6 or CDK4 at the $\mathrm{G}_{1}$ stage, which combines with retinoblastoma protein ( $\mathrm{pRb}$ ) to promote DNA transcription, allowing cells to pass the $\mathrm{G}_{1} / \mathrm{S}$ checkpoint and triggers cell proliferation (39). Overexpression of cyclin D1 may shorten the duration of the $\mathrm{G}_{1}$ stage and accelerate cell proliferation, leading to tumorigenesis (39). The overexpression and amplification of cyclin D1 are common features of cervical cancer and other malignant tumors (40) and may underlie the pathogenic process in ovarian cancer that involves the loss of OVCA1 expression $(34,41)$.

The p16 protein is an important tumor suppressor and is a member of the cyclin-dependent kinase inhibitor family (42-44). Through the competitive inhibition of cyclin D1, p16 protein is able to function directly in the process of cell cycle regulation to reduce cell proliferation (42-44). Furthermore, p16 expression levels are negatively regulated by $\mathrm{pRb}$ protein (45). Previous studies have demonstrated that the 
abnormal expression of p16 is correlated with the occurrence of cervical squamous carcinoma and CIN, and may occur in part due to the combination of the E7 carcinogenic protein of HR-HPV and pRB $(46,47)$. A previous study suggested the detection of p16 protein expression levels may be applied in the differential diagnosis of high or low level CIN (48).

Preventing cell transformation and proliferation from the $\mathrm{G}_{1}$ to $\mathrm{S}$ stage via upregulation of p16 and inhibition of cyclin D1 expression may be a possible mechanism underlying the effects of OVCA1 in ovarian cancer (21). The current study hypothesizes that, if this mechanism was disrupted, cell cycle dysregulation may occur, leading to uncontrolled proliferation of tumor cells. Therefore, the detection of cyclin D1 and p16, in addition to examining the correlations between the OVCA1 gene and cervical cancer progression, may aid the elucidation of the potential underlying mechanisms of abnormal OVCA1 expression in the development and progression of cervical lesions, and the interaction of various genes in the occurrence of cervical lesions.

In the current study, the protein and mRNA expression levels of p16 in normal cervix, CIN and cervical cancer tissues differed significantly $(\mathrm{P}<0.05)$. The protein expression of p16 in early-stage cervical cancer in the HR-HPV negative group was lower compared with cervical cancer in the advanced-stage and HR-HPV positive group $(\mathrm{P}<0.05)$. In the case of HR-HPV infection, p16 may function in the overall process of the occurrence and development of cervical lesions together with OVCA1; however, the present study observed no statistically significant differences in p16 expression between low vs. high level CIN in the early events of cervical lesions, which revealed that changes in OVCA1 expression may occur earlier compared withp16 expression. The protein and mRNA expression levels of cyclin D1 in normal cervix and cervical cancer tissue exhibited significant differences $(\mathrm{P}<0.01)$, indicating its potential participation in the development of cervical cancer. However, the protein expression of cyclin D1 in normal cervix, CIN and low vs. high level CIN tissues exhibited no significant differences $(\mathrm{P}>0.05)$, indicating that cyclin D1 may function in cervical cancer at the advanced stage or during cervical cancer metastasis. This result was consistent with a previous study, which detected a correlation between cyclin D1 expression levels and the infiltration, metastasis and deterioration of tumors, indicating that cyclin D1 may be an important prognostic indicator (24).

In the current study, statistically significant differences were identified between the protein expression levels of p16 in cervical squamous carcinoma and adenocarcinoma tissues $(\mathrm{P}<0.05)$; however, as the numbers of cases in the two groups differed greatly, this may have led to bias and the results require further study in an increased sample size. The correlations between OVCA1, cyclin D1 and p16 and the lymph node metastasis of cervical cancer exhibited no statistical significance. In addition, no significant association was observed between cyclin D1 expression and HR-HPV infection, which also requires further study with an increased number of cases.

Positive correlations were observed in all pairwise comparisons between OVCA1, cyclin D1 and p16 protein expression (all $\mathrm{P}<0.05$ ), with a more pronounced correlation between OVCA1 and p16 expression compared with OVCA1 and cyclin D1, as well as cyclin D1 and p16. For mRNA expression, only OVCA1 and p16 exhibited a significantly positive correlation $(\mathrm{P}<0.01)$. Therefore, in the occurrence and development of cervical lesions, there may be interactions among OVCA1, cyclin D1, p16 and HR-HPV infection, particularly for p16.

The occurrence and development of cervical cancer is a multi-factor, multi-stage process involving numerous genes, including a variety of oncogenes and tumor suppressors. Abnormal OVCA1 gene and protein expression and its synergistic effects with various cancer-associated genes (oncogenes, tumor suppressor genes and other regulatory factors) may be important in the occurrence and development of cervical cancer. Although the upregulation of p16 expression levels and the inhibition of cyclin D1 expression levels in ovarian cancer were possible mechanisms underlying the effects of OCVA1, there may be varied mechanisms in cervical cancer. HR-HPV infection maybe the initial factor underlying changes in cyclin D1 expression, and its synergistic effect with P16 was more pronounced than the associated functions of cyclin D1. Therefore, cyclin D1 may function in the advanced stages of cervical cancer. At present, there are few studies examining the role of OCVA1 in cervical cancer, and the associated underlying mechanisms by which OVCA1 is involved in internal functions of cells and interacts with associated genes or factors, including p16 and HR-HPV infection remain to be elucidated. OCVA1 may be a potential tumor marker and provide a novel basis for the clinical diagnosis and treatment of cervical cancer.

\section{References}

1. Apostolidou S, Hadwin R, Burnell M, Jones A, Baff D, Pyndiah N, Mould T, Jacobs IJ, Beddows S, Kocjan G and Widschwendter M: DNA methylation analysis in liquid-based cytology for cervical cancer screening. Int J Cancer 125: 2995-3002, 2009.

2. Jiang BG, Chen AE and Li ZT: Clinical and pathological characteristics of early cervical carcinoma in women under 35 years of age. Mod Pract Med 3: 141-142, 2002.

3. Liu WX: Clinieal and prognostic analysis of iuvasvie cevrical careinoma in women aged 40 and yunger (unpublished $\mathrm{PhD}$ thesis). Tianjin Medical University, 2002.

4. Yu HY and Zhang X: Clinical characteristics and prognosis of young women with cervical cancer. China Health Care Nutrition 08: 793-794, 2012.

5. Bray F, Carstensen B, Moller H, Møller H, Zappa M, Zakelj MP, Lawrence $\mathrm{G}$, Hakama $\mathrm{M}$ and Weiderpass $\mathrm{E}$ : Incidence trends of adenocarcinoma of the cervix in 13 European countrines. Cancer Epidemiol Biomarkers Prev 14: 2181-2199, 2005.

6. Wang SS, Sherman ME, Hildesheim A, Lacey JV Jr and Devesa S: Cervical adenocarcinomal and squamous cell carcinoma incidence trends among white women and black women in the United States for 1976-2000. Cancer 100: 1035-1044, 2004.

7. Castellsagué X, Díaz M, de Sanjosè S, Muñoz N, Herrero R, Franceschi S, Peeling RW, Ashley R, Smith JS, Snijders PJ, et al: Worldwide human papillomavirus etiology of cervical adenocanimoma and its cofactors: Impications for screening and prevention. J Natl Cancer Inst 98: 303-315, 2006.

8. Sasieni P, Castanon A and Cuzick J: Screening and adenocarcinoma of the cervix. Int J Cancer 125: 525-529, 2009.

9. Sun JH, Cai SM and Gao YL: Some problems in gynecologic oncology and training of Gynecologic Oncology. Zhonghua Zhong Liu Za Zhi 31: 946-948, 2009 (In Chinese).

10. Boabang P, Kurbacher CM, Waida A and Amo-Takyi BK: Detection of aberrations of chromosome 17 and p 53 gene expression and their correlation to histologic grading and prognosis in primary invasive squamous cell carcinoma of the cervix. Gynecol Obstet Invest 51: 233-239, 2001.

11. Bruening W, Prowse AH, Schultz DC, Holgado-Madruga M, Wong A and Godwin AK: Expression of OVCA1, a candidate tumor suppressor, is reduced in tumors and inhibits growth of ovarian cancer cells. Cancer Res 59: 4973-4983, 1999. 
12. Kong FD, Zhao CY, Jia LY, Miao XY, Wei W, Zhao XY, Yang G and Sun WP: Cloning of human OVCA1 gene and its in vitro inhibitory effect on ovarian cancer cell growth. Int J Lab Med 16 : 1805-1806, 2011

13. Zhu BZ: The study on the correlation of tumor suppressor gene of OVCA1 and cervical cancer (unpublished PhD thesis). Dalian Medlical University, 2010.

14. Pecorelli S: Revised FIGO staging for caicinoma of the vulva, cervix, and endometrium. Int J Gynaecol Obstet 105: 103-104, 2009.

15. Richart RM: Cervical intraepithelial neoplasia. Pathol Annu 8: 301-328, 1973

16. Cervical Intraepithelial Neoplasia (CIN) Pipeline Review, H2 2015. Research and Markets, 2016.

17. Pierre PL Martin-Hirsch, Evangelos Paraskevaidis, Andrew Bryant, Heather O Dickinson and Sarah L Keep: Surgery for cervical intraepithelial neoplasia Pierre PL Martin-Hirsch1. Cochrane Database Syst Rev CD001318, 2010.

18. Livak KJ and Schmittgen TD: Analysis of relative gene expression data using real-timequantitative PCR and the 2(-Delta Delta C(T)) method. Methods 25: 402-408, 2001.

19. Kiaer SK, Frederiksen K, Munk $C$ and Iftner T: Long-term absolute risk of cervical intraepithelial neoplasia grade 3 or worse following human papillomavirus infection: Role of persistence. J Natl Cancer Inst 102: 1478-1488, 2010.

20. Rodriguez AC, Schiffman M, Herrero R, Hildesheim A, Bratti C, Sherman ME, Solomon D, Guillén D, Alfaro M, Morales J, et al: Longitudinal study of human papillomavirus persistence and cervical intraepithelial neoplasia grade $2 / 3$ : Critical role of furation of infection. J Natl Cancer Inst 102: 315-324, 2010

21. Tong R, Yang Q and Wang CY: Research advances on tumor suppressor gene OVCA1. Lett Biotechnology 2: 258-263, 2015.

22. Schultz DC, Vanderveer L, Berman DB, Hamilton TC, Wong AJ and Godwin AK: Identification of two candidate tumor uppressor genes on chromosome 17p13.3. Cancer Res 56: 1997-2002, 1996.

23. Voeghtly LM, Mamula K, Campbell JL, Shriver CD and Ellsworth RE: Molecular alterations associated with breast cancer mortality. PLoS One 7: e46814, 2012.

24. Zhang GL, Yang H and Xu K: Loss of heterozygosity on chromosome $17 \mathrm{p} 13.3$ in ovarian cancer and cervical cancer. Zhonghua Zhong Liu Za Zhi 19: 401-403, 1997 (In Chinese).

25. Park SY, Kang YS, Kim BG, Lee SH, Lee ED, Lee KH, Park KB and Lee JH: Loss of heterozygosity on the short arm of chromosome 17 in uterine cervical carcinomas. Cancer Genet Cytogenet 79: 74-78, 1995.

26. Shikeeva AA, Kekeeva TV, Zavalishina LÉ, Andreeva IuIu and Frank GA: Allelic imbalance in patients with non-small cell lung cancer. Arkh Patol 75: 3-8, 2013 (In Russian).

27. Zhang B, Jia WH, Matsuda K, Kweon SS, Matsuo K, Xiang YB, Shin A, Jee SH, Kim DH, Cai Q, et al: Large-scale genetic study in East Asians identifies six new loci associated with colorectal cancer risk. Nat Genet 46: 533-542, 2014

28. Smardova J, Liskova K, Ravcukova B, Kubiczkova L, Sevcikova S, Michalek J, Svitakova M, Vybihal V, Kren L and Smarda J: High frequency of temperature-sensitive mutants of p53 in glioblastoma. Pathol Oncol Res 19: 421-428, 2013.

29. Kanamori M,Sano A, YasudaT,Hori T and Suzuki K: Array-based comparative genomic hybridization for genomic-wide screening of DNA copy number alterations in aggressive bone tumors. J Exp Clin Cancer Res 31: 100, 2012.
30. Ninomiya S, Tyybäkinoja A, Borze I, Räty R Saarinen-Pihkala UM, Usvasalo A, Elonen E and Knuutila S: Integrated analysis of gene copy number, copy neutral LOH, and microRNA profiles in adult acute lymphoblastic leukemia. Cytogenet Genome Res 136: 246-255, 2012.

31. Chen CM and Behringer RR: Ovcal regulates cell proliferation, embryonic development, and tumorigenesis. Genes Dev 18: 320-332, 2004

32. Kong FD, Liu L, Wei W, Zhao XY, Miao XY and Zhao CY: Tumor suppressor gene OVCAl inhibits migration and invasion of ovarian cancer cells A2780 in vitro. Chin J Cancer Biother 154: 351-355, 2008.

33. Zhang JF: The expression of OVCA1 and P53 in ovarian serous Tumors (unpublished $\mathrm{PhD}$ thesis). Dalian Medlical University, 2011.

34. Kong F, Tong R, Jia L, Wei W, Miao X and Zhao C: OVCA1 inhibits the proliferation of epithelial ovarian cancer cells by decreasing cyclin D1 and increasing p16. Mol Cell Biochem 354: 199-205, 2011

35. Liang $\mathrm{XX}$, Liang JF, Xiao H, Cheng CX, Zhao YZ and Zheng HX: Expression and clinicopathological significance of OVCA1 and HIC1 in ovarian epithelial tumors. Chinese Remedies Clinics 113: 255-258, 2011.

36. Wiper DW and Zanotti KM: Analysis of allelic imbalance on chromosome $17 \mathrm{p} 13$ in stage I and stage II epithelial ovarian cancers. Gynecol Oncl 71: 77-82, 1998.

37. Phillips NJ, Ziegler MR, Radford DM, Fair KL, Steinbrueck T, Xynos FP and Donis-Keller H: Allelic deletion on chromosome 17 p13.3 in early ovarian cancer. Cancer Res 56: 606-611, 1996.

38. Wang Q, Deng J and Jiang YX: Research progress of cyclin D1. J Modern Oncol 2: 350-353, 2009.

39. Liang S, Mu K, Wang Y, Zhou Z, Zhang J, Sheng Y and Zhang T: CyclinD1 a prominent prognostic marker for endometrial diseases. Diagnostic Pathology 8: 138, 2013.

40. Lu S, Zhang BH and Wang Z: Expression of survivin, cyclin D1, p21(WAF1), caspase-3 in cervical cancer and its relation with prognosis. J Huazhong Univ Sci Technolog Med Sci 25: 78-81, 2005.

41. Liu XL: Expression of OVCAl gene and its relation with the Expression of cyclin D1 in epithelial ovarian tissue (unpublished PhD thesis). Dalian Medlical University, 2007.

42. Kamb A: Cell-cycle regulators and cancer. Trends Genet 11 136-140, 1995.

43. Kamb A, Gruis NA, Weaver-Feldhaus J, Liu Q, Harshman K, Tavtigian SV, Stockert E, Day RS III, Johnson BE and Skolnick MH: A cell cycle regulator potentially involved in genesis of many tumour types. Science 264: 436-440, 1994.

44. Abreu Velez AM and Howard MS: Tumor-suppressor Genes, cell cycle regulatory checkpoints and the skin. N Am J Med Sci 7: 176-188, 2015.

45. Hao HB and XU PQ: Research progress of relationship between tumor suppressor gene p16 and malignant tumor. J Bengbu Medical College 3: 361-363, 2012.

46. Huang K, Li LA, Meng YG and Fu XY: p16 expression in patients with cervical cancer and its prognostic significance: Meta-analysis of published literature. Eur J Obstet Gynecol Reprod Biol 183: 64-69, 2014.

47. Cai S and Han K: Research on expression and importance of p53, p16 and VEGF-C in cervical cancer. J Gynecol Obstet Biol Reprod (Paris) 44: 639-645, 2015.

48. Krishnappa P, Mohamad IB, Lin YJ and Barua A: Expression of P16 in high-risk human papillomavirus related lesions of the uterine cervix in a government hospital, Malaysia. Diagn Pathol 202, 2014. 